Historia Contemporánea 50: 195-222

ISSN: $1130-2402$

DOI: $10.1387 /$ hc.14149

\title{
EL PARTIDO Y LA CIUDAD. MODELOS DE ORGANIZACIÓN Y MILITANCIA DEL PSUC CLANDESTINO (1963-1975)
}

\author{
THE PARTY AND THE CITY. MODELS OF \\ ORGANIZATION AND MEMBERSHIP OF THE \\ UNDERGROUND PSUC (1963-1975)
}

\author{
Giaime Pala \\ $\mathrm{UdG} / \mathrm{UAB}$
}

Entregado el 1-9-2013 y aceptado el 22-1-2014.

Resumen: Pese a que la bibliografía sobre la historia de los comunistas en España durante el franquismo ha crecido notablemente en los últimos años, nuestro conocimiento de las estructuras organizativas de las que se dotó cada realidad territorial comunista para realizar su trabajo político está aún lejos de ser satisfactorio. ¿Qué forma daban los comunistas a su estructura organizativa y qué finalidades buscaban con ella? ¿De qué manera estaba pensada para relacionarse con la sociedad? ¿Y en qué medida estas decisiones modificaban la manera de hacer política de los militantes? El presente artículo se propone responder a estas y otras preguntas investigando el caso del Partit Socialista Unificat de Catalunya (PSUC), sin duda el núcleo comunista más fuerte del país y cuya organización cambió radicalmente en el bienio 1969-1970: de una estructura vertical y poco diversificada a otra descentralizada y más abierta. Semejante cambio le permitió al partido crecer cuantitativa y cualitativamente, mantener un contacto más estrecho con la sociedad catalana y crear un marco en el que la militancia pudiera actuar de forma más autónoma y creativa respecto al pasado.

Palabras clave: Partit Socialista Unificat de Catalunya, Partido Comunista de España, organización del partido, militancia clandestina, sociedad catalana. 


\begin{abstract}
Even though the bibliography on the history of the communists in Spain during the Francoism has grown notably in the last years, our knowledge of the organizational structures that every communist territorial reality was endowed with to carry out its political work is still far from being satisfactory. Which form did the communists give to their organizational structure and for which purposes did they look with it? Which way was it thought to relate to the society? And in which measure did these decisions modify the way of doing politics of the militancy? This article proposes to answer these and other questions investigating the case of the Unified Socialist Party of Catalonia (PSUC), undoubtely the strongest communist nucleus of the country and whose organization changed radically into the two-year period 1969-1970: a vertical structure and little diversified to other decentralized and more open one. Such change allowed the party to grow quantitatively and qualitatively, to hold a closer contact with the Catalan society and to create a framework in which the militancy could act in a more creative and autonomous way than in the past.
\end{abstract}

Key words: Unified Socialist Party of Catalonia, Spanish Communist Party, Party organization, Clandestine militancy, Catalan society. 


\section{Introducción}

En la última década, los estudios sobre la historia de los comunistas españoles durante el franquismo han crecido de forma exponencial. Un fenómeno impulsado por la celebración de tres congresos científicos sobre la historia del Partido Comunista de España (PCE) y Partit Socialista Unificat de Catalunya (PSUC) y por la publicación de libros y artículos que nos han permitido mejorar notablemente nuestro conocimiento acerca de la cultura política, la práctica militante y el ideario de los comunistas en aquellos años ${ }^{1}$. Con todo, una lectura atenta de esta misma producción nos indica que uno de los aspectos que aún merece ser profundizado por los historiadores es el del tipo de organización que las distintas federaciones y realidades territoriales comunistas se dieron para realizar su trabajo político, esto es, qué forma daban a su estructura organizativa y qué finalidades buscaban con ella, en base a qué motivaciones la escogían, de qué manera estaba pensada para entrar en contacto e influir en la sociedad, si y en qué medida favorecía un mejor funcionamiento del partido y qué consecuencias tenía este tipo de decisión en la manera de militar de los comunistas. El objetivo del presente artículo es examinar estas cuestiones y sacar algunas conclusiones que nos ayuden a valorar su alcance historiográfico de cara a una más exhaustiva comprensión de la trayectoria del mundo comunista. Para ello, se estudiará aquí el caso del PSUC, el partido, como ha sido definido recientemente, «del antifranquismo catalán» ${ }^{2}$ y la más fuerte, desde un punto de vista tanto cualitativo como cuantitativo, de las organizaciones comunistas activas en España en la última dé-

${ }^{1}$ Manuel Bueno, Carmen García, José Hinojosa (coords.), Historia del PCE: I Congreso, 1920-1977, II volúmenes, Fundación de Investigaciones Marxistas, Madrid, 2007; Giaime Pala (ed.), El PSU de Catalunya, 70 anys de lluita pel socialisme. Materials per a la història, Ediciones de Intervención Cultural, Mataró, 2008; Manuel Bueno Lluch y Sergio Gálvez Biesca (eds.), Nosotros los comunistas. Memoria, identidad e historia social, Atrapasueños, Sevilla, 2009. Para un análisis de la bibliografía reciente sobre la historia del comunismo español, véase: Francisco Erice, «Tras el derrumbe del muro. Un balance de los estudios recientes sobre el comunismo en España», Ayer, n. 48, 2002, pp. 315-330; Manuel Bueno Lluch y Sergio Gálvez Biesca, «Un paso más en el proceso de "normalización historiográfica" de la historia del PCE», Cuadernos de historia contemporánea, n. 27, 2005, pp. 317-330; David Ginard Féron, «The spanish historiografy of communism: light and shade of following the fall of the Wall (1989-2008)», Revista de historiografía, n. 10, 2009, pp. 26-41.

2 Carme Molinero y Pere Ysàs, Els anys del PSUC. El partit de l'antifranquisme (1956-1981), L'Avenç, Barcelona, 2010. 
cada de la dictadura franquista. En definitiva, estudiar el segmento más sólido del área política más robusta de la oposición antifranquista.

\section{Del partido vertical al partido horizontal y descentralizado}

Para encuadrar correctamente la tipología y la funcionalidad de la organización del PSUC en los años del tardofranquismo, es preciso remarcar un primer dato: su enorme dificultad para crear y mantener una estructura estable en el área metropolitana de Barcelona desde el mismo año 1939 a causa de la represión policial ${ }^{3}$. Un problema que fue siempre presente en la vida de los comunistas catalanes pero que se agravó en 1957 con la detención del responsable del Comité de Barcelona, Emiliano Fábregas, y de las de los hombres que el partido envió posteriormente para hacerse con las riendas del partido: Miguel Núñez (1958), Carlos Rebellón (1960) y Pere Ardiaca $(1962)^{4}$. Se entiende, pues, por qué el partido apenas creció en aquellos años y los motivos de su fragilidad. El Comité de Intelectuales, uno de los pocos sectores del PSUC que funcionaban a pleno ritmo gracias a su completa autonomía, después de la detención de Ardiaca envió una nota al Comité Ejecutivo en la que se le avisaba de que, si no acometía cambios radicales que estabilizaran a la organización, el partido no habría tardado en desaparecer ${ }^{5}$. En ello estuvo la dirección comunista residente en París, la cual encargó la reorganización del PSUC a tres militantes enviados adrede desde Francia: Leonor Bornao, Josep Salas y Manuel Valverde. El primer paso fue reorganizar en 1963 el partido en la capital catalana, dividiéndolo en tres sectores: hacia el este de la calle Roger de Flor hasta Sant Adrià y Sant Andreu; de la calle Roger de Flor hacia el oeste hasta la calle Urgell; y de la calle Urgell hasta L'Hospitalet;

${ }^{3}$ Al respecto, véase: José Luis Martín Ramos, Rojos contra Franco. Historia del PSUC, 1939-1947, Edhasa, Barcelona, 2002; Antoni Lardín Oliver, Obrers comunistes. El PSUC a les empreses catalanes durant el primer franquisme (1939-1959), Cossitània, Valls, 2007.

${ }^{4}$ Sobre todas estas detenciones, hay que consultar la abundante documentación conservada en el Archivo Histórico del Partido Comunista de España (en adelante AHPCE), Fondo Represión franquista, caja 41, «Proceso de Emiliano Fábregas y su grupo»; «Proceso de Miguel Núñez y su grupo»; caja 42, «Proceso de Carlos Rebellón y su grupo»; «Proceso de Pere Ardiaca y su grupo».

5 AHPCE, Fondo Represión franquista, caja 42, «Información del Comité de Intelectuales», 25/12/62. 
éstos eran los llamados sectores 1,2 y 3 , cuyos micro-comités dirigían la actividad de las células que operaban en su territorio de competencia y que respondían a tres tipos: células de sectores profesionales, de empresa y de lugar de estudio ${ }^{6}$. A su vez, el Comité de Barcelona dirigía las operaciones de los compañeros de Badalona, L'Hospitalet, Santa Coloma de Gramenet y de todo el Baix Llobregat, manteniendo, además, un contacto estrecho con los núcleos comarcales del Vallès y del Maresme. Esta primera reforma permitió al partido apuntalar su organización después de la inestabilidad de los años anteriores. El liderazgo de Salas, Bornao y Valverde fue bueno, aunque estuvo caracterizado por una evidente dependencia de las instrucciones del exterior. En otras palabras, nunca daban un paso sin consultar a París, lo que explica que la correspondencia de los años 1963-1967 sea la más numerosa que se conserva en los archivos del PCE/PSUC.

Por lo tanto, el PSUC metropolitano llegó a finales de los sesenta con un modelo organizativo fuertemente centralizado (por su dependencia del Comité de Barcelona y del Comité Ejecutivo) y, como detallaremos más adelante, construido en torno al lugar de trabajo del militante. Dicho modelo, que a partir de mediados de 1968 pasó a dirigir el recién salido de la cárcel Miguel Núñez en calidad de nuevo responsable del Comité de Barcelona $^{7}$, entró en crisis el año siguiente, cuando el gobierno declaró en el mes de enero el Estado de Excepción. En efecto, la policía consiguió detener a más de cien militantes de Barcelona y provocar la huida de sus hogares de otros cien ${ }^{8}$, además de descubrir cómo funcionaba toda la estructura del partido gracias a las confesiones que, bajo tortura, obtuvo de algunos de los detenidos ${ }^{9}$. El peligro de que esto ocurriera estaba implícito en el modelo organizativo del PSUC barcelonés: si la policía lograba son-

${ }^{6}$ Arxiu Personal de Francesc Vicens, apuntes reuniones del Comité Ejecutivo del PSUC, «Emili sobre la situació del Partit a Barcelona», 16/8/63.

${ }^{7}$ Acerca del nombramiento de Miguel Núñez como responsable del Comité de Barcelona, cargo que ocuparía hasta la legalización del PSUC en 1977, consúltese AHPCE, Fondo PSUC microfilm 1839, «Carta de Latorre» (Gregorio López Raimundo), 8/6/68.

8 AHPCE, Fondo PSUC, caja 58, «Carta de Latorre», 7/3/69.

9 Se puede ver la reconstrucción que hizo la policía de la organización del PSUC en Archivo Histórico del Gobierno Civil de Barcelona (en adelante AHGCB), caja 120, Actividades Contra el Régimen (1968-1969), «Partido Socialista Unificado de Cataluña», Nota Informativa de la Jefatura Superior de Policía de Barcelona, 18/2/69. Sobre las consecuencias de las confesiones de algunos de los comunistas detenidos, véase: AHPCE, Fondo PSUC, caja 58, «Carta de Saltor» (Miguel Núñez), 8/3/69. 
sacar información a un militante, su célula debía disolverse y sus integrantes esconderse para no ser arrestados; y si conseguía detener a uno de los dirigentes de su sector territorial, automáticamente todo este sector (que representaba el 33\% de la organización de la ciudad) podía estar en peligro dada la cantidad de información que aquel poseía sobre su territorio de competencia. Esto fue lo pasó en aquellos meses de emergencia debido a la identificación - y, en algunos casos, a la detención - de los cuadros dirigentes más importantes de los tres sectores. En la práctica, durante todo el año 1969 la actividad del PSUC se redujo al mínimo. Con todo, lo peor fue la reacción de la militancia a las consignas de una dirección que había calificado el Estado de Excepción de acto de «extrema debilidad y avanzada descomposición del régimen dictatorial del General Franco» ${ }^{10}$. A partir de la primavera de 1969, el Comité Ejecutivo empezó a recibir numerosas noticias que describían el descontento de los militantes acerca del insensato triunfalismo manifestado por sus dirigentes, quienes no protegieron a una organización que había resultado totalmente inadecuada para afrontar una situación de emergencia que otorgaba a la policía más poderes de lo normal ${ }^{11}$. Como confesó un miembro del Comité de Barcelona en un desolador informe para la dirección de París, no sólo «existe en muchos militantes de distintos comités una profunda desconfianza en algunos camaradas de la dirección», sino que el Comité Ejecutivo no podía ocultar, y ocultarse, que «la organización en Barcelona es la que peor ha resistido el estado de excepción en toda España» ${ }^{12}$.

Fue en medio de esta crisis que el secretario de organización del PSUC, Josep Serradell, redactó en abril de 1969 un primer documento con vista a analizar las deficiencias organizativas del partido y aportar elementos de reflexión basados sobre «datos extraídos de la realidad» ${ }^{13}$.

10 Arxiu Nacional de Catalunya (en adelante ANC), Fondo PSUC, n. 128, «La respuesta al estado de excepción. Declaración del Comité Ejecutivo del PSUC», 6/2/69.

11 AHPCE, Fondo PSUC, caja 58, «Carta de Saltor», 10/5/69; «Informe de Mirò», 10/5/69; «Conversa de Miró celebrada amb el company Navarro», 14/5/69; «Resolución de la célula de Nous Horitzons sobre la Resolución del C.E. del PCE», mayo de 1969. En cuanto a los poderes de la policía, hay que recordar que, con la declaración del Estado de Excepción, se supendían los artículos 12, 14, 15, 16 y 18 del Fuero de los Españoles y se otorgaba a las fuerzas de seguridad más libertad para los plazos legales de detención.

${ }_{12}$ Arxiu Històric de Comissions Obreres de Catalunya (en adelante AHCO), Fondo Centre de Treball i Documentació, cajas PSUC, «Informe a la dirección del Partido», 1969.

13 AHPCE, Fondo PSUC, caja 52, carpeta 3, «Reflexiones sobre organización», abril de 1969. Aunque el informe no lleve firma, es muy evidente por su contenido que fue re- 
Los acontecimientos de los meses del estado de excepción habían puesto de manifiesto todos los límites de un partido cuya forma había sido pensada según una orientación demasiado jerárquica y vertical, lo que causaba: «a) Falta de orientación. Sobre todo en las cuestiones de aplicación de la línea general a la práctica (...); b) Falta de dinámica e iniciativa. No es impulsada en la medida de lo necesario la dinámica individual existiendo la tendencia a consultar todos los pasos en una medida que obstaculiza la combatividad de los militantes. La iniciativa de los camaradas es mirada generalmente por parte de los cuadros responsables con reticencia y desconfianza (...); c) Idea de disciplina impuesta de arriba abajo. Falta de una disciplina colectiva considerándose más importante seguir lo que viene de arriba por ese simple hecho, que lo que se decide en reuniones regulares (...); d) Falta de confianza de la base hacia los responsables» ${ }^{14}$.

La suma de las dificultades individuales de cada militante provocaba una serie de disfunciones para plasmar la organización del partido según las formas de la sociedad civil. En resumen, el problema del PSUC residía en que sus estructuras se habían quedado desfasadas ante una sociedad que evolucionaba rápidamente, sobre todo en los barrios, donde «la vida del partido se desarrolla en un circuito cerrado sin apenas repercusión. No hay orientación clara referente a la perspectiva de lucha en los barrios, su ampliación de la base popular democrática. Los camaradas se limitan a estar (...) Actualmente no existe ningún organismo coordinador a nivel de partido (ni a otro nivel) que relacione camaradas inmersos en la lucha en los barrios» ${ }^{15}$. Es por eso por lo que Serradell aconsejaba una reforma del PSUC metropolitano que se basara en los siguientes organismos: 1) «células de barrio», en las que militarían todos los militantes de cada barrio, incluidos aquellos que ya militaban en las células de empresa, que debían aceptar la «doble militancia» (en las células de su barrio y en las de su puesto de trabajo); 2) «comités de barrio», que estarían formados por los responsables de las células de barrio y que tendrían autonomía para dinamizar la lucha en cada barrio; 3 ) «comités de ciudad», formados

\footnotetext{
dactado por Serradell (quien, por otra parte, en abril de 1969 se encontraba en París, ciudad que figura como lugar en el que se redactó el documento. Su vuelta a Barcelona, según la documentación de archivo, es datable en la primera semana de mayo).

$14 \mathrm{Ibid}$. Igual que en todas las otras citas que aparecen en este trabajo, los subrayados y las negritas figuran en el texto original.

15 Ibid.
} 
por los responsanbles de cada comité de barrio y que tendrían autonomía para impulsar la lucha en cada ciudad.

Antes de ver cómo fueron aplicadas las reflexiones de Josep Serradell, es necesario detenernos aquí en el concepto de «doble militancia», que aparecía por primera vez en la vida del partido. Como hemos dicho, hasta 1969 el militante comunista desempeñó su militancia tendencialmente en un solo frente de lucha. Así, el universitario y el profesor lo hacían en la Universidad o en el sector de intelectuales, el estudiante en el Instituto, el trabajador en la fábrica o en la oficina, etc. Se creía que, de tal manera, el partido podía arraigar en todos los ámbitos de la producción material e intelectual de la sociedad y dar una respuesta satisfactoria a las demandas de cada estamento social. En el fondo, este modelo reflejaba la visión que tenía el partido de la sociedad civil: la de una gran fábrica marcada por una división del trabajo que obligaba a los trabajadores (los militantes) a ocuparse de sus tareas específicas en la cadena de montaje (sus sectores de militancia), cuyos resultados tenían que ser ensamblados por la dirección superior (la cúpula del partido) para producir la mercancía final (la «Huelga Nacional Pacífica» que provocaría la ruptura con el franquismo $)^{16}$. Al militante-trabajador se le prometía el control del producto final, aunque desconocía casi todas sus fases de fabricación. Pero la sociedad catalana se había revelado mucho más sofisticada que una fábrica: en ella convivían simbióticamente toda una serie de realidades y de capas sociales que encajaban mal en un tipo de análisis tan lineal.

Para Serradell, era preciso ir más allá de este esquema y situar al militante de base en un contexto de trabajo más variado y complejo. Sólo mediante una inserción total y efectiva, el comunista podía tener una panorámica global del mundo en el que vivía, y para eso era urgente obligar al militante a incrementar los «ritmos de producción» política y ejercer, de hecho, una doble militancia en el puesto de trabajo y en su barrio. Estas propuestas fueron recogidas por el Comité de Barcelona y debatidas ya a mediados de $1969^{17}$. De lo que se trataba era de seguir las indicaciones que Santiago Carrillo expuso en un famoso artículo publicado con el título «Salir a la superficie». En él, el secretario general del PCE se limitaba a oficializar una práctica que se había consolidado en el movimiento obrero

16 Una buena descripción de lo qué debía ser la Huelga Nacional Pacífica es la que ofrece Jesús Sánchez Rodríguez en su libro Teoría y práctica democrática en el PCE (1956-1982), Fundación de Investigaciones Marxistas, Madrid, 2004, pp. 56-63.

17 AHPCE, Fondo PSUC, caja 58, «Carta de Saltor», 10/5/69. 
y estudiantil: infiltrarse en las organizaciones legales de masas y transformarlas en instrumentos de oposición al régimen. Igual que los obreros que habían formado las Comisiones Obreras a través del Sindicato Vertical, o los estudiantes que enuclearon el Sindicato Democrático de Estudiantes de las estructuras del Sindicato Español Universitario, el partido debía fundirse con las plataformas cívicas y demostrar a las masas «que es posible vivir de otra forma, que ellas pueden jugar un papel social y político activo, que el franquismo les niega» ${ }^{18}$. Semejante proyecto era posible solamente si el partido tenía el coraje de cuestionar hasta el final los últimos residuos de la vieja concepción del partido de vanguardia y ultraclandestino, y si cambiaba su estructura para acercarla a las necesidades de cada realidad urbana. Para eso, y en línea con las indicaciones de Serradell, el PSUC concretó una auténtica descentralización, que en sus documentos llamó también «territorialización». En efecto, a partir de 1970, los núcleos comunistas de las ciudades de Badalona, L'Hospitalet, Santa Coloma de Gramenet y del Bajo Llobregat contaron con comités dirigentes completamente desvinculados de un Comité de Barcelona que, a su vez, se transformó de organismo dirigente a «supervisor» de los nuevos instrumentos políticos del partido en la ciudad condal: los comités de barrio.

Si ya en el informe sobre organización presentado por Isidor Boix en el VI pleno ampliado del Comité Central del PSUC de septiembre de 1971, se dio noticia de los cambios realizados ${ }^{19}$, el documento que nos proporciona más datos sobre el proceso de descentralización es un informe de 1973 del Comité de Barcelona redactado casi seguramente por Miguel Núñez. En sus páginas podemos aclarar el alcance de las reformas adoptadas y el verdadero motivo que las impulsaron: «Pasar de un Comité de Barcelona y tres comités de sector territorial, con la existencia complementaria de unas organizaciones profesionales estructuradas al margen de la organización territorial, a la existencia de un total de 12 Comités del Partido, organizados sobre la base territorial, además del Comité de SEAT y del Comité Universitario, constituye sin duda un paso fundamental para dotar a nuestro Partido de la organización que necesita en Barcelona (...) Cuando hablamos de proceso de descentralización incluimos en esta denominación dos procesos distintos que se han desarro-

18 Santiago Carrillo, «Salir a la superficie», Nuestra Bandera, n. 65, III trimestre de 1970, p. 15 .

19 ANC, Fondo PSUC, n. 50, «El reforzamiento del Partido y las cuestiones de organización. Informe presentado por Ignasi Bruguera» (Isidor Boix), septiembre de 1971. 
llado simultáneamente. Uno, el que podemos llamar descentralización organizativa, cuyo objetivo principal consiste en establecer organizaciones de ámbito más reducido, facilitando de este modo la aproximación de nuevos cuadros a los comités. Otro, el podríamos llamar desectorialización, que nos ha llevado a la desaparición de los comités de frente de lucha, para ir incorporando las células y militantes de estas organizaciones a las organizaciones de carácter territorial» ${ }^{20}$.

La desaparición de los comités de «frentes de lucha» había comportado la disolución de aquellos sectores de profesionales que habían funcionado durante más de una década, como el de los intelectuales, cuyo comité fue disuelto en dos etapas: la primera se produjo en diciembre de 1971, cuando se optó por desmembrarlo para dar vida a los micro-comités profesionales de enseñanza, sanidad, técnicos, medios de comunicación, abogados y profesores no numerarios de Universidad; en una segunda etapa, éstos habían ido desapareciendo para integrarse en las estructuras territoriales ${ }^{21}$, por lo que en un comité de barrio podían trabajar un médico, un obrero, una ama de casa o un estudiante, quienes tenían que presentar soluciones consensuadas para cualquier problema de su zona. Esto era lo que el partido definía «la globalización de los problemas», es decir, que cada militante abandonara el trabajo especializado y estuviera preparado para involucrarse en todas las cuestión que afectaran a la población.

En 1973, ya estaban consolidados los 12 comités territoriales del Partido en Barcelona: Casco Antiguo, Eixample, Gracia, Poble Nou, Sant Andreu, Besòs, Horta-Guinardò, Zona Franca, Trinitat, Sants, Sarriá-Sant Gervasi y Nou Barris. Para proporcionar una línea unitaria entre todos los comités, se puso en marcha un nuevo organismo, el Comité de Barcelona Ampliado (CBA), cuyo objetivo era «crear el marco adecuado para realizar la discusión política global de la aplicación de la política del Partido en Barcelona»22. El CBA se constituyó con los camaradas que en aquel momento componían el Comité de Barcelona y con los responsables políticos de los distintos comités y de las organizaciones de las principales empresas. Como enlaces entre el CBA y los distintos comités territoriales se instituyeron tres grandes secretarías de organización: las de «movimiento obrero»,

\footnotetext{
20 ANC, Fondo PSUC, n. 857 (I), «Las tareas políticas y de organización en Barcelona», 1973.

${ }^{21}$ Ibid. Y también, AHCO, Fondo Centre Treball i Documentació, cajas PSUC, «Resolución sobre la integración del Comité de Sanidad en los sectores territoriales», 1972.

22 Ibid.
} 
«fuerzas de la cultura»y «movimiento popular» ${ }^{23}$. Estas secretarías estaban formadas, además de por sus coordinadores generales, por los responsables territoriales de estos tres ámbitos de lucha y su cometido era proporcionar un mínimo - e indispensable - nivel de homogeneidad política a todos los comités, dado que ya habían sido disueltos los «frentes de lucha».

La descentralización supuso un cambio palmario en el funcionamiento del PSUC metropolitano: de una estructura piramidal basada en la cadena Comité Ejecutivo-Comité de Barcelona-Comités locales-sectores de trabajo, se pasó a otra más horizontal por la cual los comités territoriales (tanto de Barcelona como del extrarradio) tuvieron una autonomía amplísima para que pudieran «decidir ellos en concreto» ${ }^{24}$ la política a llevar a cabo en sus territorios de competencia. Además, la reforma del Comité de Barcelona (que, no olvidemos, representaba más de la mitad del partido en Cataluña) conllevó una visión distinta del militante de base respecto al pasado. Frente a una concepción mecánica del militante como ejecutor de las órdenes de la dirección, se implantó otra que hacía más sutil y borrosa la distinción entre dirigentes y dirigidos de weberiana memoria: todo comunista debía saber dirigir la lucha de masas y poder articular su trabajo sin recurrir constantemente a las indicaciones de la cúpula. «Acostumbrar a que los militantes anden solos», como declaró un miembro del Comité Central en $1973^{25}$, fue el leitmotiv de los documentos del partido hasta la legalización: «En las grandes coyunturas políticas que van a surgir en el proceso de lucha de masas, la agilidad, la capacidad de dirección, la iniciativa revolucionaria propia de cada Comité del Partido sin esperar a las orientaciones del Comité de Barcelona, actuando con decisión y audazmente en la aplicación de la línea política trazada por el Partido, va a ser una cuestión esencial, la característica principal del Partido que a la hora de la HGP y la HN, necesitamos. Es más, esta agilidad e iniciativa debe ser igualmente característica de cada militante individual en los momentos que de su decisión dependa la lucha de masas» ${ }^{26}$.

23 AHCO, Fondo Centre de Treball i Documentació, apuntes manuscritos de Miguel Núñez, «Comité de Barcelona», 1973; y también, AHPCE, Fondo PSUC, caja 59, «Carta de Saltor», 22/10/73.

${ }^{24}$ AHCO, Fondo Centre de Treball i Documentació, cajas PSUC, «Comunicado del Comité de Barcelona a los comités del Partido», febrero de 1974.

25 ANC, Fondo PSUC, n. 21, «Resum i anotacions de les intervencions en els plenaris del III Congrés del PSUC», febrero de 1973.

${ }^{26}$ ANC, Fondo PSUC, n. 857 (I), «Las tareas políticas y de organización del Partido en Barcelona», 1973. 


\section{La sociopolítica del barrio: de las Comisiones de Barrio a las Asociaciones de Vecinos}

Como consecuencia de las primeras reflexiones sobre el papel del partido en el barrio y el proceso de descentralización, el PSUC, junto con otras fuerzas políticas, organizó hacia 1969-1970 unas denominadas «Comisiones de Barrio» (CB). Éstas eran organismos ilegales formados por los representantes de los partidos antifranquistas cuyo fin era apoyar y mantener un contacto con el nuevo movimiento obrero de las Comisiones Obreras y dar orientación política a los problemas de los barrios catalanes. A falta de un estudio sistemático sobre las CB, algunos autores, como Anna Alabart, han señalado que las CB no sólo tuvieron «influencia» y «poder de convocatoria», sino que fueron la base sobre la que pudo desplegarse el fenómeno de las Asociaciones de Vecinos según una dinámica de continuidad: «[1a CB] era la semilla del movimiento vecinal, pero, para poder crecer, hacía falta buscar una nueva fórmula, legal, que les posibilitase una proyección más amplia. La asociación de vecinos era la mejor manera de conseguir este objetivo, ya que suponía la legalización de la comisión de barrio» ${ }^{27}$. Tal vez haya que matizar este juicio. Por de pronto porque las CB no lograron, salvo casos puntuales como los de Terrassa y Sabadell, ligar el barrio a la fábrica e implicar a personas que no fuesen militantes de partidos políticos. Y en segundo lugar, porque sería mejor hablar de ruptura entre las Comisiones de Barrio y las Asociaciones de Vecinos, y no de evolución de las primeras a favor de las segundas. O, cuando menos, esto fue lo que pensó la dirección del PSUC.

En 1971, el Comité de Barcelona encargó a un experto en el tema un informe sobre las Comisiones de Barrio a partir del cual se pudiera discutir toda la estrategia en este frente ${ }^{28}$. El documento empezaba con una autocrítica sobre el papel -o, mejor, sobre el no-papel- del PSUC en los barrios durante la etapa 1939-1968: «Las empresas son el centro del partido de la actividad del Partido y demás fuerzas. Lógica consecuencia de la represión posterior a la guerra civil y a la derrota de las fuerzas populares (...) Acciones como el 51 en Barcelona o el 57 o el intento

27 Anna Alabart, «Las asociaciones de vecinos: las conquistas y las facturas», en VV.AA., Nuestra Utopía. PSUC: 50 años de historia de Cataluña, Planeta, Barcelona, 1986, pp. 66-67.

28 AHPCE, Fondo PSUC, caja 59, «Esquema para la discusión de la política del Partido en los barrios», 22/4/71. 
de la Huelga General del 59, responden a una radicalización reivindicativa espontánea del pueblo o a una llamada política "por arriba" en otra, pero jamás a la actividad cotidiana de organizaciones de masas en las barriadas» ${ }^{29}$. El éxito de las Comisiones Obreras en la segunda mitad de los sesenta había empujado al partido a copiar su modelo y aplicarlo en los barrios mediante la creación de unas Comisiones de Barrios que, igual que las primeras, se proponían ser «movimientos sociopolíticos». Sin embargo, en la práctica las CB se habían transformado en simples correas de transmisión entre el movimiento obrero organizado y la ciudad, centrando su atención en las tareas de solidaridad con los trabajadores despedidos e intentando imitar sin éxito el modelo de Terrassa, cuyos barrios «vivían» de la fábrica y por eso estaban dispuestos a una mayor implicación con ella. El barrio, pues, era visto todavía como un frente auxiliar de la lucha obrera «y las $C B$ fueron transformándose rápidamente en "apéndice acti-

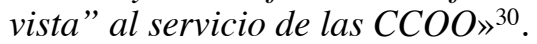

$\mathrm{Al}$ obrerismo había que añadirle el vanguardismo, ya que en las Comisiones de Barrio era fuerte la tendencia al secretismo y menosprecio de las plataformas legales existentes en los barrios: «Es evidente que la mayoría de las CB han nacido "desde fuera" mismo del barrio para "ir al barrio", es decir, que hay una toma de conciencia de ligarse a las masas, pero no una relación directa (traducida por la representación social de los sectores más afectados del barrio) con el barrio» ${ }^{31}$. Tal concepción impedía a las CB contactar con toda aquella población, la gran mayoría, no politizada y poco propensa a inmiscuirse en exasperantes reuniones secretas que, para colmo, tampoco tenían en cuenta sus exigencias reales. Era imposible pedirles a los vecinos que entraran en las CB tal y como estaban estructuradas: ello hubiera significado obligarlos a asumir un compromiso político para el cual no estaban preparados. Ni que decir tiene que su carácter obrerista chocaba con la realidad sociológica de aquellos barrios - como los barceloneses de Gràcia, Sants o el Eixample - caracterizados por la fuerte presencia de una pequeña y mediana burguesía culturalmente antifranquista pero harto distante de las demandas de CCOO. Al respecto, para el autor del informe la solución residía en realizar cambios en la manera de concebir y hacer funcionar estas Comisiones, iniciando por el mismo destinatario de su acción: «La cuestión ha es-
29 Ibid.
${ }^{30}$ Ibid.
31 Ibid. 
tado planteada durante bastante tiempo en el sentido de saber hasta qué punto las $C B$ eran en sí Movimiento obrero organizado (las Comisiones Obreras de Barrio) y por lo tanto eran parte del Movimiento Obrero, o bien las $C B$ respondían a un movimiento popular (de base social más amplia), que debía tener una necesaria relación con el MO, pero como movimiento con cierta autonomía. Creo que la segunda tesis es la válida» ${ }^{32}$. Fue a partir de aquí que tomó fuerza el concepto de «movimiento popular», demasiado a menudo identificado con el movimiento obrero y que, en cambio, incluía a estratos sociales diversos que las CB debían entender y con los que tenían que trabajar. Por eso, era preciso: «1) Prestar especial atención a la base social de las Comisiones de barrio, rehuyendo la propensión fácil a reclutar en los elementos politizados del barrio; 2) Tomar contacto con todos los centros legales del barrio (asociaciones de vecinos, peñas regionales, centros culturales diversos, centros recreativos, etc.). Ello sería difícil si se pretende que el contacto con estos centros se realice mediante su integración en la $C B$ (sectarismo)» ${ }^{33}$.

El cambio de paradigma es palmario: no era la sociedad civil la que tenía que entrar en el espacio de las CB, sino que eran las CB las que tenían que entrar en los espacios de la sociedad civil y empaparse de ella. Pero, ¿era posible alcanzar estos objetivos con los mismos medios? Mientras que para el autor del informe las CB podían seguir siendo útiles, para el Comité de Barcelona eran ya unos instrumentos anacrónicos por su naturaleza demasiado «política» y poco «social». Por muchas reformas que se hubiesen realizado, éstas jamás lograrían fundirse con la sociedad. Estaba claro que se habían de encontrar alternativas y no fue casualidad que el secretario general del PSUC, Gregorio López Raimundo, en su informe para el III Congreso del PSUC de 1973 no sólo no citó a las CB en el apartado dedicado a la lucha en los barrios, sino que hizo hincapié en la nueva metodología a seguir para avanzar en este terreno: «En los barrios, como en los centros de trabajo y estudio, el movimiento o movimientos de masas sólo pueden ser realmente de masas si tienen un carácter abierto, si se apoyan en formas de acción y organización legales o paralegales, si son de todos y no sólo de los revolucionarios. Los partidos y grupos revolucionarios deben mantener, también a nivel de barrio, formas de relación clandestina que consideren necesarias. Pero han de evitar el error

\footnotetext{
32 Ibid.

33 Ibid.
} 
- frecuente en el último periodo-de pretender dar vida a movimientos de masas "clandestinos", basados en la reunión u organización exclusiva de los revolucionarios» ${ }^{34}$.

Estas indicaciones se volvieron viables gracias al surgimiento, en la primera mitad de la década de los setenta, del nuevo movimiento vecinal encuadrado en las Asociaciones de Vecinos. Por ahora, es imposible establecer las causas exactas del nacimiento de cada una de estas plataformas legales en Cataluña. Probablemente, antes de escribir su historia general y definitiva, habrá que estudiar en detalle un buen número de ellas como hizo Ricard Martínez con la sabadellense «Can Oriach» ${ }^{35}$. Aún así, las mejores investigaciones sobre el tema, como la de Anna Alabart o las que han coordinado Carme Molinero y Pere Ysàs, apuntan a que las AA.VV. fueron el fruto de la confluencia de varios elementos entre los cuales destacan una situación urbanística deficitaria y la falta de servicios básicos a causa de una insuficiente inversión pública por parte de las instituciones del régimen, el empuje reivindicativo procedente de la sociedad civil y el trabajo de personas que, más o menos relacionadas con los partidos de izquierdas, supieron amplificarlo en clave política ${ }^{36}$. En particular, el PSUC pudo entrar y trabajar eficazmente en las AA.VV. gracias a la creación de los comités de barrio en la provincia de Barcelona, cuya autonomía operativa y conocimiento del territorio les agilizaban la labor de infiltración. Ahora sí adquiría un valor añadido la desmembración de los sectores profesionales, puesto que los comités podían incorporar en los grupos de trabajo de las entidades vecinales (sanidad, cultura, movimiento obrero, urbanismo, etc.) a camaradas preparados para coordinar las reivindicaciones de la población. De modo que el comunista se transformó, en el barrio, de militante en activista, en creador

34 ANC, Fondo PSUC, n. 18, «III Congreso del PSUC. Informe del Comité Central presentado por Gregorio López Raimundo», febrero de 1973.

35 Ricard Martínez, El moviment veïnal a l'area metropolitana de Barcelona durant el tardofranquisme i la transició: el cas de Sabadell (1966-1976), tesina de doctorado, Universidad Pompeu Fabra, Barcelona, 1999.

36 Anna Alabart, Els barris de Barcelona i el moviment associatiu veïnal, tesis doctoral, Universidad de Barcelona, 1981; Carme Molinero y Pere Ysàs (coords.), Construint la ciutat democràtica. El moviment veïnal durant el tardofranquisme i la transició, Icària, Barcelona, 2010. Asimismo, siguen siendo útiles los siguientes trabajos: Equipos de Estudio, La lucha en los barrios en Barcelona, Elías Querejeta, Madrid, 1976; Jordi Borja, Qué son las asociaciones de vecinos, La Gaya Ciencia, Barcelona, 1976; Manuel Vilasero y Josep Maria Huertas Claveria, «Los barrios de Barcelona en conflicto», en Centro de Investigación y Documentación Urbana y Rural, Las asociaciones de vecinos en la encrucijada: el movimiento ciudadano en 1976-1977, Ediciones de la Torre, Madrid, 1977. 
de movimiento a través de iniciativas sociopolíticas dirigidas a «diversificar el campo de actuación (jubilados, enseñanza, carestía de vida, etc.), elaborando plataformas reivindicativas y lanzando campañas concretas capaces de aglutinar a los vecinos y evitar la dispersión que a menudo nos hace perder fuerza» ${ }^{37}$, conforme con el objetivo de «llevar el centro de decisión a las masas mismas, de poner aquí el acento» ${ }^{38}$. En suma, el partido dejó de «ir al barrio» para «ser barrio», volcándose en un sinfín de actividades que supieron recoger todas las demandas populares: desde la recuperación de la lengua y tradiciones catalanas, los cursos de alfabetización y educación sexual y la explicación de los perjuicios de los planes urbanísticos municipales hasta las campañas a favor de una sanidad y educación gratuitas y modernas, la recuperación de monumentos y zonas verdes, la construcción de centros sociales y bibliotecas, etc. ${ }^{39}$ En las entrevistas a antiguos militantes comunistas realizadas por el equipo de investigadores del Archivo Histórico de Comisiones Obreras de Cataluña, es fuerte el recuerdo de un activismo atípico respecto de las viejas formas de hacer política del partido pero que creaba consenso y un nuevo sentido común en las interrelaciones sociales de la comunidad: "Les associacions de veïns estaven dominades pel PSUC. Vull dir, és que érem a tot arreu (...) La gent del PSUC estava al carrer. Et sortia un diumenge a arreglar una plaça $i$ eren els primers que agafaven l'aixada $i$ els sacs de terra i era gent que pencava (...) Diràs, potser era més important fer política $i$ estar amb una reunió... pues potser no era tan important això com anar amb els veïns a fer una plaça i aconseguir que aquella plaça, que era un vertedero d'escombraries, quedés neta un diumenge. I això la gent ho veia» ${ }^{40}$. Este testimonio apunta bien al círculo virtuoso que se estableció entre el partido y las Asociaciones de Vecinos por el cual, cuanto más crecía el primero más crecían las segundas, y viceversa. El funcionamiento abierto de éstas, su régimen asambleario para tomar las decisiones importantes, el método electivo para la selección de los dirigentes y las múltiples formas de participación de sus miembros (comisiones y grupos de trabajo, delegaciones, etc.), eliminaron los últimos residuos de la menta-

37 ANC, Fondo PSUC, n. 858, «Sobre algunos problemas del movimiento popular en los barrios de Barcelona. Secretaría de Movimiento Popular», febrero de 1974.

38 ANC, Fondo PSUC, n. 859 (I), «Las tareas políticas y de organización en Barcelona», 1973.

${ }^{39}$ Una interesante muestra de estas actividades en ANC, Fondo PSUC, de número 2350 a 2394.

${ }^{40} \mathrm{AHCO}$, colección de entrevistas orales, entrevista a Montserrat Milià. 
lidad vanguardista del partido y favorecieron, poco a poco, la afiliación de nuevas personas que se iban desprendiendo de la imagen demoníaca de los comunistas inculcada por el franquismo ${ }^{41}$. Finalmente, el PSUC encontró, después de las Comisiones Obreras, el otro movimiento sociopolítico que necesitaba para enlazar el mundo del trabajo con la sociedad civil, y no lo dejó escapar. Son numerosas las cartas del Comité Ejecutivo en las que éste no cejaba de pedir un incremento del trabajo en las AA.VV. ya «infiltradas» y de entrar en aquellas todavía vírgenes, como reclamó Josep Serradell a los comunistas de Lleida, avisándoles del descontento de la Asociación de Vecinos del barrio de Santa María de Gardeny debido al retraso de la entrega de 303 pisos prometidos por el Ministerio de Vivienda ${ }^{42}$.

La gran ventaja de entrar en estas asociaciones era la invisibilidad. Los comités territoriales del PSUC enviaban a sus militantes a las AA.VV. no en cuanto comunistas, sino como ciudadanos comprometidos con la gente del barrio. Y como tales, se ganaban la confianza de los demás socios y empezaban su trabajo político. La policía, que estaba al corriente de los movimientos que se ocultaban detrás de las Asociaciones de Vecinos, se veía imposibilitada para actuar por la falta de pruebas directas que hubieran podido desarticular al PSUC y por temor a activar en la población una reacción de solidaridad con los detenidos. En el Archivo del Gobierno Civil de Barcelona se conservan una serie de informes de las fuerzas de seguridad en los que éstas reconocían, como en el caso de Nou Barris, la dificultad de intervenir en las AA.VV. inflitradas por el PSUC y otros partidos de izquierdas «para llevar a cabo tareas de agitación, proselitismo y captación de nuevos militantes»: «La ASOCIACIÓN DE VECINOS 9 BARRIOS ha sido objeto constante de vigilancia y observación por parte de los servicios específicos de la Brigada Regional de Investigación Social de esta Jefatura Superior, sin que hasta el momento presente se hayan podido obtener los suficientes elementos probatorios, para proceder a la desarticulación de todas aquellas actividades subversivas que, de una manera solapada y encubiertas, se vienen realizando a través de las mismas» ${ }^{43}$.

41 ANC, Fondo PSUC, n. 858, «Sobre algunos aspectos del movimiento popular en los barrios de Barcelona. Secretaría de Movimiento Popular», 1974.

42 AHPCE, Fondo PSUC, caja 59, «Nota sobre una circular informativa de la Asociación de Vecinos de Santa María de Gardeny», marzo de 1974.

43 AHGCB, Ayuntamiento de Barcelona (1974-1975), caja 52, «Semblanza políticosocial sobre la Asociación de vecinos del sector Vallbona-Torre Baró-Trinidad ( 9 barrios)», Nota Informativa de la Jefatura Superior de Policía de Barcelona, 11/8/74. 
La población como escudo y la legalidad como medida profiláctica contra la represión; mientras que la caída de un miembro de una Comisión de Barrio hubiera afectado solamente a la misma por ser expresión de los partidos, la detención de un dirigente vecinal habría significado malquistarse con un ámplio número de ciudadanos de a pie por el daño que podía granjear a la asociación, y por inocularles la sensación - no siempre advertida - de que el poder podía atrapar a todo el mundo, incluso a aquellos que pedían sólo un espacio verde, una guardería o un semáforo. Como en Mataró, el PSUC entró en los barrios haciéndose con el control de centros sociales, bibliotecas y grupos culturales, etc., desde donde puso en práctica la consigna de crear un nuevo partido de masas ${ }^{44}$. O como en Terrassa, ciudad en la que los comunistas se infiltraron en 25 de las 60 entidades legalmente reconocidas (desde las culturales y recreativas hasta las económicas y corporativas), llegando a ocupar cargos directivos en las asociaciones de vecinos y en la de los «Amigos de las Naciones Unidas» ${ }^{45}$. Con todo, el caso de Barcelona es el más emblemático de todos, como demuestra un informe de enero de 1975 de Miguel Núñez en el que se traza una perfecta radiografía de la situación del PSUC en cada uno de los comités de la ciudad y del que conviene citar, a modo de ejemplo de la capacidad del partido de adaptarse al territorio, la fuerza que éste tenía en un barrio como el de Sants, caracterizado por la presencia de fábricas y talleres y por un sólido tejido asociativo: «Organización de Sants. Territorialmente agrupa Sants, Hostafranchs y Las Corts. 61 militantes, 51 regulares y 10 irregulares. En un año ha crecido en un $120 \%$ el número de militantes, ha extendido su influencia organizada a Las Corts y Hostafranchs. Cuenta con un comité territorial de 6 miembros que se reúne semanalmente y otro ampliado de 12, que lo hace cada de tres semanas. Dispone, asimismo, de tres comités intermedios: Las Corts, Distrito VII y taxistas (...) Zonas de influencia política: Empresas: AFA, Manufacturas Cerámicas, Elbe S.A., INTER. Relación con los despedidos de SEAT. Centros de masas: Centro Social de Sants (camarada en la junta), Comisión Gestora de la Asociación de Vecinos de Hostafranchs (camarada en la junta), Asociación de Vecinos de Las Corts (5 camaradas en la junta), UEC, Centro Católico de Sants, Centro Excursionista, Orfeò de Sants, Centro de Ciclismo, Parroquia de San Medir y la de Santa María. Ligazón con la junta de comerciantes de Salvador Anglada y los núcleos de Solidaridad.

\footnotetext{
${ }_{44}$ AHGCB, CC.OO., caja 302, «Informe sobre un Centro Social de Mataró», sin fecha.

45 AHPCE, Fondo PSUC, caja 59, «El papel del Partido en entidades y organismos legales. Comité Local de Terrassa», junio de 1974.
} 
Parroquia de Las Corts, Ateneo de Montserrat. Relación con guarderías "Guimbó", "Pau", y escuelas "Barrufeta" y "Lavinia" ${ }^{46}$.

No tenemos datos tan precisos acerca de las demás ciudades catalanas, pero por las consideraciones contenidas en los informes de organización podemos deducir que, en las localidades del cinturón metropolitano, la influencia debió de ser muy parecida. Es evidente que el PSUC clandestino fue un partido urbano, porque llevar la lucha con la sociedad civil era posible solamente en aquellas localidades caracterizadas por una alta densidad urbana o una tradición asociativa consolidada, donde el recuerdo del obrerismo cenetista y de la tradición republicana de los primeros treinta años del siglo XX no habían sido totalmente borrados por la tentativa de aniquilación cultural del régimen. En este sentido, el caso del PSUC parece tener puntos en común con el de la organización madrileña del PCE, cuyo análisis sobre la importancia de la lucha en los barrios inició a mediados de los sesenta y cuya intensa labor en la lucha vecinal le permitió convertirse en el partido hegemónico de la oposición antifranquista en la capital ${ }^{47}$. Tanto en el caso catalán como en el

46 AHCO, Fondo Centre de Treball i Documentació, «Informe d'organització. Barcelona», 1975.

47 Marcello Caprarella y Fanny Hernández Brotons, «La lucha por la ciudad: vecinos-trabajadores en las periferias de Madrid, 1968-1982», en Vicente Pérez Quintana y Pablo Sánchez León (eds.), Memoria ciudadana y movimiento vecinal, Los Libros de la Catarata, Madrid, 2008, pp. 46-47. Estos puntos en común que se pueden notar en las contribuciones del libro editado por Pérez Quintana y Sánchez León (voluntad del PCE de diseñar una política para los barrios, infiltración en las AA.VV., autonomía de las células comunistas operantes en el área metropolitana, capacidad para implicar a trabajadores de otras regiones de España residentes en Madrid, etc.) deberían confirmarse a través de un estudio ad hoc sobre la labor en los barrios del PCE madrieño, del que ahora carecemos. De la misma manera, sería útil confrontar el caso del PSUC con la acción desplegada por el PCE en otras ciudades más pequeñas que también experimentaron vivaces movimientos vecinales. Para una visión de conjunto de algunas de estas realidades, véase: Víctor Manuel Urrutia Abaigar, El movimiento vecinal en el área metropolitana de Bilbao, Instituto Vasco de Administración Pública, Bilbao, 1985; Roberto Germán Fandiño, Historia del movimiento ciudadano e historia local: el ejemplo del barrio de Yagüe en Logroño (1948-1975), Instituto de Estudios Riojanos, Logroño, 2003; Javier Contreras Becerra y María Candelaria Fuentes Navarro, «El movimiento vecinal en Granada y Jaén. Nuevas perspectivas para su estudio, 1964-1981», en Rafael Quirosa-Cheyrouze Muñoz y Mónica Fernández Amador (coords.), Sociedad y movimientos sociales, Instituto de Estudios Almeriense, Almería, 2009, pp. 467-482; Constantino Gonzalo Morell, Democracia y barrio. El movimiento vecinal en Valladolid, Universidad de Valladolid, Valladolid, 2008. 
madrileño, los comunistas formaban a políticos y se formaban ellos mismos como ciudadanos, incluso allí donde el partido estaba compuesto principalmente por personas que procedían de otras zonas de España en las que las agregaciones sociales colectivas no eran moneda corriente ${ }^{48}$. Una escuela, en fin, de democracia.

\section{Crecimiento y finanzas del partido}

En 1968, el PSUC dirigido o coordinado por el Comité de Barcelona (Barcelona ciudad, Hospitalet, Badalona, Sant Andreu, Bajo Llobregat, Santa Coloma y algunos pueblos cercanos) contaba con 949 militantes, de los que 146 eran de la Juventud Comunista y 75, mujeres ${ }^{49}$. Respecto a 1967, el partido había visto ingresar en sus filas a 307 nuevos afiliados, pero aún incluyendo a las demás organizaciones (Terrassa, Sabadell, Tarragona, Lleida, Mataró, Girona, etc.), difícilmente podía contar con más de 1500 militantes en toda Cataluña. Una cantidad, por otra parte, superior al resto de las federaciones regionales del PCE, incluidas Asturias y Madrid ${ }^{50}$. Un nuevo avance se produjo a raíz de la campaña de proselitismo «Lenin» lanzada en 1970, gracias a la cual se pudieron cooptar a 834 nuevos militantes y a otros 424 para la Juventud Comunista. En cifras absolutas, ocupaba el primer lugar la organización de Barcelona con 273 ingresos (más otros 75 para la JC). También destacaban los ingresos en la Universidad (90), SEAT (30), Baix Llobregat (73) y Santa Coloma-Badalona (93). Según los datos ofrecidos por Josep Serradell, en Cataluña existían entonces 105 ciudades y pueblos con más de 5000 habitantes y el partido estaba presente en 71 de ellos, y en 27 de las 60 localidades de 3000 a 5000 habitantes (además de tener militantes aislados en unos 50 pueblos con menos de 3000 habitantes) $)^{51}$. Casi seguramente, cuando terminó la

48 José Luis López Bulla, Cuando hice las maletas, Península, Barcelona, 1997, pp. 73-74.

49 AHPCE, Fondo PSUC, «Organització», sin fecha (aunque, casi seguramente, enero de 1969).

50 AHPCE, Documentos PCE, «Datos estadísticos de militancia en el partido por provincias», junio de 1967.

51 ANC, Fondo PSUC, n. 48, «La campanya per un partit més fort i arrelat a les masses i al treball d'organització. Informe de Josep Román» (Josep Serradell), septiembre de 1970. 
campaña «Lenin» el PSUC debía contar con una cifra de militantes cercana a los 2500 .

El periodo que va de 1971 a 1975 se caracterizó por un crecimiento más lento pero constante, fruto de la política de descentralización y de una penetración paulatina en la sociedad. Según un informe sobre cotizaciones en el que figuran los afiliados de las principales ciudades del país, el partido contaba a principios de 1974 con 2847 militantes $^{52}$, a los que hay que añadir los 431 de los pueblos pequeños que registró el responsable de comarcas del PSUC entre 1972 y $1973^{53}$. Ahora bien, sumando también a los de la Juventud Comunista (570 en 1971 y quizás cerca de 1000 en 1975) y a los cerca de 400 activistas del grupo Bandera Roja que entraron en el PSUC en otoño de $1974^{54}$, y teniendo presente que el partido debió de crecer a lo largo de 1975, podemos dar por buena la cifra de entre 5.000 y 5.500 militantes comunistas cuando se produjo la muerte del general Franco, esto es, una cantidad algo superior a los 4.500 militantes que contabilizó Gregorio López Raimundo en noviembre de $1974^{55}$. En seis años el partido había triplicado sus fuerzas, si bien el $80 \%$ de ellas actuaban en la provincia de Barcelona. En las restantes provincias, y aparte de los núcleos de las ciudades de Tarragona y Lleida, el PSUC era una fuerza todavía marginal o, como en algunas comarcas gerundenses, meramente testimonial. A partir de 1976, el partido experimentó una auténtica avalancha de ingresos que alcanzó los 40000 afiliados en ocasión del IV Congreso de noviembre de $1977^{56}$. Entraban así una serie de personas en un tiempo en que la clandestinidad se transformó, por decirlo con una expresión usual en la prensa del partido, en una «legalidad de hecho» reconocida definitivamente después del mitin

52 ANC, Fondo PSUC, n. 418, «Secretaría de Finanzas del PSUC», año 1974.

53 El dato de 431 militantes en pueblos pequeños lo hemos obtenido del análisis de dos informes que redactó el responsable de comarcas del PSUC, Josep Maria Pardell alias «Roure», a saber: AHPCE, Fondo PSUC, caja 59, «Comissió de Comarques. Les organitzacions del partit per comarques», 1972; «Algunes informacions de les organitzacions del Partit a comarques», abril de 1973.

54 Giaime Pala, «Una semilla de discordia. La entrada de Bandera Roja en el PSUC», Revista HMiC: Història Moderna i Contemporània, n. 9, 2011, pp. 140-162.

55 AHPCE, Fondo PSUC, microfilm 2618, «Carta de Nogués» (Gregorio López Raimundo), noviembre de 1974.

56 Partit Socialista Unificat de Catalunya, PSUC. IV Congrés, amb la veu de tots, Laia, Barcelona, Laia, 1977, p. 31. 
de Terrassa de mayo de $1976^{57}$ y en el que el PSUC comenzó a aparecer en público en distintas localidades sin que la policía pudiese intervenir ${ }^{58}$; personas que conocían al partido y podían haber entrado en contacto anteriormente con él pero que, posiblemente, evitaron la militancia activa por miedo a la represión que podía caerles encima. Decir esto no supone minimizar el valor político de cada cual ni juzgar su actitud resistencial, sino poner en evidencia que estos nuevos afiliados ya se movían en una óptica posclandestina y que el verdadero «militante comunista clandestino» terminó el 20 de noviembre de 1975.

Hay un último aspecto que nos resultará útil para acabar de comprender por qué el PSUC creció en la primera mitad de los setenta y, como veremos al final de este apartado, cómo se convirtió en una organización descentralizada y formada por militantes más autonómos. Nos referimos al problema de las finanzas, que el partido se empeñó en solucionar desde que, en 1971, optó por mantenerse definitivamente independiente del $\mathrm{PCE}^{59}$.

57 Sobre el mítin de Terrassa, consúltese el artículo «LA FORÇA DELS COMUNISTES. Gran míting a Terrassa», Treball, n. 443, 7/6/76, p. 1. En cuanto a la conciencia de que con ese acto se estuviera legalizando de facto al PSUC, véanse las memorias del entonces gobernador civil de Barcelona, Salvador Sánchez-Terán, De Franco a la Generalitat, Planeta, Barcelona, 1988, pp. 107-108. Respecto a la estrategia comunista de ir imponiendo su presencia antes de ser legalizado, es muy útil la nota informativa que remitió la Jefatura Superior de Policía de Barcelona a Sánchez-Terán, «Programa de actuación del Partido Comunista de España. 9 de marzo de 1976», consultable en AHGCB, caja 497.

58 El PSUC salió definitivamente «a la superficie» en julio de 1976 con una serie de actos para festejar su 40 aniversario. Sobre la no intervención de la policía para prohibirlos (impuesta por Sánchez-Terán) véase, a modo de ejemplo: AHGCB, caja Notas Guardia Civil, caja 496, «Conferencia sobre el PSUC en San Vicente de Castellet», 7/7/76; «Acto político en conmemoración del 40 aniversario del PSUC en Manresa», 5/7/76; «Presentación del PSUC en Mataró. Julio de 1976».

${ }^{59}$ La decisión de seguir siendo independiente, el PSUC la tomó en 1971 y la hizo pública en el artículo «En el 35 aniversari de la fundació del Partit Socialista Unificat de Catalunya. Declaració del Comité Executiu», suplemento especial de Treball, n. 331, junio de 1971 , p. 2. De este modo, los dirigentes catalanes concluían un debate durado más de quince años y en el que, en más de una ocasión, pidieron sin éxito la integración del PSUC en el PCE. Al respecto, véase: AHPCE, Documentos PCE, Actas Congresos, «V Congreso del PCE. Intervención de Rafael Vidiella», agosto 1954; ANC, Fondo PSUC, n. 39, «Sobre el document del Comitè Central del Partit Comunista d'Espanya. Intervención de Pere Ardiaca», octubre de 1959, pp. 67-68; AHPCE, Documentos PCE, Plenos Comité Central, «VII Congreso del PCE. Intervención de Gregorio López Raimundo», agosto 1965; Gregorio López Raimundo, «La palanca per a la conquesta del pervindre», Nous Horitzons, n. 8, IV trimestre de 1966, pp. 10-15. 
Desde el final de la Guerra Civil, los comunistas catalanes siempre habían dependido económicamente del PCE para acabar de sufragar sus gastos tanto del interior como del exterior. Obviamente, no era lo mismo una organización como el PCE que podía recaudar fondos en todo el territorio español que otra que actuaba en un territorio mucho más pequeño como es Cataluña. Además, era el PCE quien manejaba los contactos y las ayudas procedentes de los países del socialismo real y de los partidos comunistas de Europa, como el francés. Estaba claro que una independencia real tenía que fundamentarse en la independencia económica del hermano mayor, como explicó López Raimundo poco antes de la legalización ${ }^{60}$. La de la autonomía financiera se transformó en los últimos años de la clandestinidad en una de las consignas más repetidas por la dirección, o, mejor dicho y a juzgar por el tono de sus documentos, en una verdadera obsesión. Quien visite las hemerotecas podrá constatar la aparición continua e insistente en la prensa del PSUC de llamamientos en los que se avisaban a los militantes de que «iSin la independencia económica, no puede haber independencia política! Nosotros somos, y queremos ser, un partido independiente» ${ }^{61}$. No era solamente una cuestión de dinero, sino de orgullo: el partido había de demostrar su mayoría de edad en todos los sentidos, que podía andar solo y sin complejos por el mundo. Por eso, cuando el Secretariado del PSUC pidió por última vez en 1973 una ayuda económica al PCE, lo hizo no sin cierta incomodidad y sin dejar de remarcar, a modo de captatio benevolentiae, el objetivo de la autofinanciación ${ }^{62}$.

Para conocer la economía del PSUC en los años del tardofranquismo es preciso presentar algunas tablas con todos los gastos y entradas registradas en los balances de la secretaría de finanzas que se conservan en el Archivo del PCE en Madrid, y sacar las debidas reflexiones. Más concretamente, adjuntaremos un cuadro de compendio que engloba los datos esenciales de las cajas del partido desde 1965 a 1975, a saber:

60 Xavier Vinader, Josep Ramoneda, José Martí Gómez, López Raimundo. La soledad del corredor de fondo, Laia, Barcelona, 1976, pp. 77-78.

61 ANC, Fondo PSUC, n. 418, «Informe del secretario de finanzas. Diciembre 1975-Enero 1976».

62 AHPCE, Fondo PSUC, caja 59, «El Secretariado del C.C. del PSUC al Secretariado del C.C. del PCE», 6/10/73. 
Balance finanzas. Entradas y salidas del año 1965 a $1975^{63}$

\begin{tabular}{ccccc}
\hline Años & Total entradas & Total salidas & Déficit & Beneficios \\
\hline 1965 & $106.690,04$ frs. & $153.998,19$ frs. & $47.308,15$ frs. & \\
1966 & $100.369,41$ frs. & $146.649,22$ frs. & $46.279,81$ frs. & \\
1967 & $96.764,93$ frs. & $165.196,79$ frs. & $68.401,86$ frs. & \\
1968 & $140.483,45$ frs. & $151.951,17$ frs. & $11.467,72$ frs. & \\
1969 & $110.694,82$ frs. & $156.592,21$ frs. & $45.897,39$ frs. & \\
1970 & $124.879,97$ frs. & $157.853,18$ frs. & $32.973,21$ frs. & \\
1971 & $101.091,28$ frs. & $156.201,26$ frs. & $55.109,98$ frs. & \\
1972 & $92.901,47$ frs. & $120.788,33$ frs. & $27.886,86$ frs. & \\
1973 & $77.853,98$ frs. & $77.675,04$ frs. & & 178,94 frs. \\
1974 & $118.846,90$ frs. & $118.846,90$ frs. & & $21.039,71$ frs. \\
1975 & $101.046,42$ frs. & $101.046,42$ frs. & & $16.628,90$ frs. \\
\hline
\end{tabular}

Este cuadro nos muestra cómo el PSUC alcanzó la independencia económica en 1973-1974. Si se presta atención a las cifras presentadas se notará que las entradas del Comité Ejecutivo no sólo no aumentaron con los años sino que, en 1973, llegaron a su mínimo histórico: 77.835,98 francos frente a los 106.690,04 de 1965. Nunca el partido había recaudado una cantidad tan misérrima. Sin embargo, el objetivo de la autofinanciación pudo alcanzarse gracias a un drástico recorte en los gastos realizados: 77.675 francos de 1973 frente a los 153.998,19 de 1965. Es decir, la dirección ingresaba y gastaba poco. Dicha dinámica se produjo paralelamente al proceso de descentralización organizativa del que ya hemos hablado: a partir de 1970, los comités territoriales de Barcelona y los comités comarcales empezaron a gestionar directamente parte del dinero recaudado en el interior, como las cotizaciones de los militantes, de las que un $30 \%$ se quedaban en los respectivos comités para subvencionar sus actividades ${ }^{64}$,

63 AHPCE, Fondo PSUC, caja 53, «Balanços de finances: entradas i sortides anys 1965-1975».

${ }^{64}$ En la página 127 de su libro Estimat PSUC (Empúries, Barcelona, 1997), Carme Cebrián afirma que el partido cobraba más a los sectores profesionales (sanidad, abogados, enseñanza, etc.) que a los obreros, en virtud de su salario más alto. El dato no es cierto: en realidad, el PSUC cobraba el 1\% del sueldo mensual a todos los militantes que trabajaban y 25 pesetas mensuales a las militantes amas de casa, a los jubilados y a los miembros de la Juventud Comunista. Véase, al respecto: ANC, Fondo PSUC, n. 201, «A los Comités del PSUC. El Secretario de finanzas», septiembre de 1973. 
o la venta de la prensa ${ }^{65}$. Las cotizaciones y la prensa eran las fuentes básicas de las finanzas de los comités junto a las campañas de autofinanciación que el partido solía lanzar periódicamente. El incremento del número de militantes permitió contar con nuevos recursos: en 1972 el PSUC vio incrementar un $112 \%$ la cantidad recaudada de las cotizaciones respecto al año anterior ${ }^{66} \mathrm{y}$, en 1975 , un $34 \%$ respecto a $1974{ }^{67}$. En cuanto a la propaganda, es preciso señalar que, a partir de 1972, el partido instaló casi todas sus imprentas en Cataluña, lo que facilitó el abaratamiento de los costes de transporte y de distribución amén de un incremento de la producción: en 1971 el PSUC imprimió, entre revistas, documentos, octavillas y boletines, 824.776 folios ${ }^{68}$; en 1974 , cuando ya contaba con una red de imprentas desplegadas por el territorio, llegó a producir más del doble: 1.967.87969. En los archivos se conservan algunas estadísticas sobre el tiraje de las distintas revistas que el PSUC publicaba en toda Cataluña ${ }^{70}$. Un ejemplo significativo de ellas es el que hace referencia a Combat, el órgano de propaganda del Comité local de Mataró, cuyos militantes consiguieron distribuir, en mayo de 1974, 3020 ejemplares en todo el Maresme y en otras comarcas cercanas ${ }^{71}$. Aún suponiendo que se vendieran solamente la mitad de estos 3000 ejemplares, la suma recaudada bastaba para cubrir los gastos de imprenta; y si no bastaba, se recurría a los siempre crecientes ingresos de las cotizaciones. Pero también hay que recordar que el tercer pilar en el que se sustentaba la economía del partido eran las intensas campañas de financiación: la campaña de los «cinco millones de pesetas» de 1969, la «Lenin» de 1970 y la de los «seis millones» de ayuda al periódico Treball de 1973-1974 eran todas iniciativas que la dirección emprendía con el fin de acelerar el trabajo de sus militantes y producir beneficios extras. Un informe de 1974 del PSUC de Terrassa describe con claridad el tipo de iniciativas llevadas a cabo en una de estas campañas: desde la venta de calendarios, postales y botellas de vino hasta la organización de rifas, la regularización de las cotizaciones de los militantes y un

65 ANC, Fondo PSUC, n. 201, «A los Comités del PSUC. El Secretario de finanzas», septiembre de 1973.

66 Ibid.

67 ANC, Fondo PSUC, n. 201, «El Secretario de finanzas», mayo de 1975.

68 AHPCE, Fondo PSUC, caja 59, «Material editado en 1971».

69 AHPCE, Fondo PSUC, caja 59, «Material editado desde el mes de marzo del 73 al 12 de julio del 74».

70 ANC, Fondo PSUC, n. 607, «Distribució clandestina de la informació», 1971-1976.

71 ANC, Fondo PSUC, n. 607, «Combat. 1974». 
mayor empeño en la venta de la prensa ${ }^{72}$. En poco más de cinco meses el Comité de Terrassa había recaudado 125000 pesetas, una cifra que normalmente representaba su presupuesto medio anual.

Un estudio atento de todas estas campañas demuestra que, aparte del dinero, su objetivo era recomponer las filas de las varias organizaciones, que a veces tendían a estancarse en su trabajo, e impulsar una optimización de todos los recursos disponibles (empezando por los humanos) que hiciera posible el funcionamiento a pleno ritmo del militante. Eran las campañas productivistas que brindaban a la organización la posibilidad de mostrar su fuerza, de conocerse y darse a conocer entre la población. Naturalmente, el volumen de militancia producido en estas ocasiones podía aguantarse sólo durante unos cuantos meses, aunque era lo suficiente para ir revitalizando la economía del partido y dar nueva linfa a la lucha, como confirman los 8.032.475 millones de pesetas que el PSUC consiguió su-

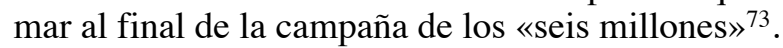

En conjunto, hacia 1974 se había establecido un funcionamiento que, para explicarlo de una manera clara y sencilla, preveía un cerebro - la dirección de París y su aparato- que contaba con sus recursos, y un cuerpo - el resto de la organización en el interior - que ya había conseguido la autofinanciación. El eje de las finanzas del partido ya se había desplazado definitivamente a Cataluña a raíz de la descentralización, como confirmó la dirección en su última petición de ayuda dirigida al $\mathrm{PCE}^{74}$.

Por último, es importante añadir algunos datos acerca de los cuadros «profesionales» y «semiprofesionales», esto es, aquellos que recibían un sueldo por su trabajo de partido a tiempo completo o parcial. Un informe de la secretaría de finanzas del PSUC de 1969 resume los gastos del aparato del interior de esta manera: 6 militantes profesionales que cobraban 12.000 pesetas mensuales, 5 semiprofesionales con sueldos que variaban entre las 8.000 y las 4.000 pesetas, 3 que trabajaban de una manera temporal en Barcelona y que cobraban 12.000 pesetas al mes y, finalmente, dos militantes del aparato de propaganda que recibían una compensación por las horas perdidas en su trabajo legal a causa de sus tareas militan$3 / 3 / 74$.

72 AHPCE, Fondo PSUC, caja 59, «Balance de campaña. Comité Local de Terrassa»,

73 ANC, Fondo PSUC, n. 201, «El secretario de finanzas», mayo de 1975.

74 AHPCE, Fondo PSUC, caja 59, «El Secretariado del C.C. del PSUC al Secretariado del C.C. del PCE», 6/10/73. 
tes $^{75}$. Si en 1969 eran 16 los militantes que recibían un sueldo o una compensación económica por su actividad, en 1975 esta cifra había subido a 27 a raíz del fuerte crecimiento que había experimentado el partido en la primera mitad de los setenta. El sueldo de un profesional había subido a 14.000 pesetas más el dinero para el alquiler, los transportes y los gastos de propaganda y funcionamiento (tinta, papel, manutención de la maquinaria de propaganda, etc. ${ }^{76}$. A pocos meses de la muerte de Franco, el PSUC podía presumir de un aparato dirigente amplio, activo y autosuficiente económicamente.

Como ya hemos señalado, más allá del objetivo - ciertamente fundamental - del PSUC de completar su independencia política con la independencia económica, la cuestión de las finanzas tiene una doble importancia: por un lado, porque el partido logró el fin deseado responsabilizando a los militantes de la financiación de sus actividades políticas, lo que impulsó aquellas descentralización y autonomía del militante que anduvo buscando desde 1969; y por el otro, porque este tipo de autofinanción permitió al PSUC aumentar considerablemente la cantidad de material de propaganda impresa: un factor esencial para una organización sin acceso a los medios de comunicación legales y que potenció el reclutamiento de nuevos activistas. De manera que el estudio de la economía del partido también contribuye a explicar los motivos por los cuales, mientras los demás grupos de izquierdas (nacionalistas, socialistas y extrema izquierda) no pasaban de ser partidos de cuadros, el PSUC contaba con una militancia numerosa y, sobre todo en la provincia de Barcelona, con un creciente arraigo en la sociedad civil. Era «El Partido», el único partido, tal y como lo entenderíamos hoy en día, realmente operante a la sazón en Cataluña.

\section{A modo de conclusión}

El análisis del modelo organizativo y del tipo de activismo de los militantes del PSUC, nos proporciona dos factores fundamentales para comprender el éxito de este partido durante el tardofranquismo: su adherencia a las características sociales del territorio catalán y la autonomía de la que

75 AHPCE, Fondo PSUC, caja 58, «Carta del Secretariado de finanzas del PSUC al Secretariado del C.C. del PCE», 1970.

76 ANC, Fondo PSUC, n. 418, «Entrades i sortides mes de gener de 1975». 
disfrutaron los militantes para desplegar su acción. El primer punto remite a una reflexión que, no por venir tarde (1969) y como consecuencia de la crisis que padeció el partido con ocasión del Estado de Excepción, deja de ser capital: la importancia del espacio urbano a la hora de hacer política; el arquitrabe de toda la práctica del PSUC fue su voluntad de comprender la fisonomía socioeconómica de las realidades urbanas de Cataluña y actuar una remodelación de su organización en consecuencia. El resultado de ello fue la descentralización del partido, que supuso la creación de nuevos comités de barrios y ciudad dotados de un amplio margen de decisión y capacitados para adaptar su labor a los territorios en los que operaban. De ahí que el PSUC se convirtió en una estructura reticular y menos dependiente del Comité Ejecutivo, lo cual, a su vez, llevó a la dirección a permitir que la militancia desarrollara su trabajo político con mucha más discrecionalidad respecto al pasado. El éxito del PSUC como mayor partido del antifranquismo catalán se debió en buena parte a esta capacidad para responsabilizar a sus activistas y otorgarles protagonismo en la lucha, sin la que tampoco se entiende su crecimiento cuantitativo y el conseguimiento del objetivo de la independencia económica del PCE (gracias precisamente a un sistema por el cual los varios comités del partido tenían que autofinanciar sus actividades sin esperar dinero de la dirección residente en Francia). En definitiva, su éxito consistió en dejar de ser un organización de vanguardia y en sentar las bases para convertirse en un partido de masas.

Queda aún por investigar el alcance del impacto - señalado en no pocas de las entrevistas a antiguos militantes comunistas conservadas en el Archivo Histórico de Comisiones Obreras de Cataluña - que tuvo el final de estos modelos de organización y militancia descentralizados y abiertos a partir de 1977, cuando la cúpula del PSUC, en nombre la política de consenso democrático que llevó a cabo en las instituciones durante los años de la Transición a la democracia, tendió a recentralizar el proceso de toma de decisiones en todos los ámbitos del partido. Y si ello se convirtió en una de las causas que deterioraron la vida interna del PSUC hasta su dramática implosión, consumada entre el V Congreso de enero de 1981 y el VI Congreso de marzo de 1982. De lo que no cabe duda es de que, por los recuerdos que reflejan las ya citadas entrevistas, el tipo de militancia practicada en los años del tardofranquismo dejó una huella profunda y sumamente positiva en la memoria de los comunistas de la época. 